\title{
Analyzing French Onomatopoeia in Webtoon 'Wonderwall' by Sena Loli
}

\author{
T Zuleika ${ }^{1}$, R L Tobing ${ }^{2}$ \\ Graduate School, Yogyakarta State University, Yogyakarta, Indonesia ${ }^{1,2}$ \\ $\left\{\underline{\text { tika.zuleika2016@student.uny.ac.id }}{ }^{1}\right\}$
}

\begin{abstract}
The technology development has started a new page. Webtoon is one form of technology development. Webtoon is an image that has a story, or commonly we called as comics and published to the internet. We can read a webtoon using an application on our phone. LINE webtoon is one of the digital comic reading application that can be accessed for free and has many different titles and genres. This research is a qualitative study which was aimed to describe the type and meaning of onomatopoeia in webtoon. The subject of this research is webtoon entitled 'Wonderwall' episode 1-10 by SenaLoli, which had been translated into French. Data were collected by using an observation method with uninvolved conservation observation technique and note-taking technique. Then, analysis of data uses an integral method to describe the type and meaning of onomatopoeia simultaneously. The results of the analysis showed that in webtoon 'Wonderwall' by SenaLoli there are five types of onomatopoeia that is 1) onomatopoeia that imitate the sound of human, 2) onomatopoeia that imitates the sound of animal, 3) onomatopoeia that imitate the sound of nature, 4) onomatopoeia that imitates the sound of object, 5) onomatopoeia that imitate the sound of daily human activities. There are four meanings of onomatopoeia that used in the webtoon 1) onomatopoeia as an indicator of the situation, 2) onomatopoeia as a forming of the character emotions, 3) onomatopoeia as a forming the name of actions, and 4) onomatopoeia to give a certain effect for the reader.
\end{abstract}

Keywords: Onomatopoeia; Webtoon; LINE Webtoon; Sena Loli

\section{Introduction}

In recent years, comics can be read freely by the public through an application. One application that provides free online comics is LINE webtoon that can be downloaded for free and it provides a variety of comic genres. Online comics can be said to be more efficient and affordable. A recent study proves that there is an influence of social media LINE webtoon to the interest in reading comics. The results of the study indicate that social media LINE webtoon affects and increases the students' reading interest [1]. In comics or webtoons, we often find onomatopoeia or imitate sounds. Onomatopoeia is the result of a sound replica that is more or less the same as the original sound and is arbitrary. The difference in onomatopoeia words is strongly influenced by the difference in the sound of phonemes contained in different 
languages because each language has its phoneme. These variations occur because each language user interprets onomatopoeic words following their phonological system and culture [2]. This research will discuss the type and meaning of French onomatopoeia in webtoon entitled 'Wonderwall' made by a creator from Indonesia, Sena Loli.

\section{Literature review}

One of the most natural and unexplored objects for the study of the mimetic elements in language is the onomatopoeia, as it implies an imitative-driven transformation of a sound of nature into a word. Onomatopoeia is typically described as involving the use of words which imitate sounds. The study of onomatopoeia is often approached through theories of sound symbolism. Onomatopoeias aim at imitating sounds produced by people, animals, nature, machines, and tools. The last three categories are particularly challenging for imitation, as sounds are not produced by another vocal system and therefore imply strong imitative efforts [3]. Enckell and Rézeau [4] define onomatopoeia as an imitated word of the sounds (humans, animals, nature, things, etc.). They make a thematic classification of onomatopoeia which imitates the sound of human, animal, nature, object, daily human activities, social life and hobby, natural sound, and abstraction. According to Seyyedi and Akhlaghi [5], Onomatopoeia is a figure of speech and is especially useful for rhetorical effect. A good example of the onomatopoeic words is in the comic books which the lettering of these onomatopoeic words enhances the beauty of comic books effectively. Another expert states that onomatopoeia aims at mimicking the sound are produced of people, animals, nature, machines, and tools [3]. The way of interpretation of the origin of the sound, according to Stephen Ullman [6], onomatopoeia differentiates into primary onomatopoeia and secondary onomatopoeia. Primary onomatopoeia is an imitation of the sound from the sound, the form is a clone of the produced sound, and secondary onomatopoeia is not because of the sound, but as a movement, size, represented by emotive tone sounds. This research particularly discusses the meaning of onomatopoeia and knowing the meaning of onomatopoeia in a comic or webtoon can help the reader to understand the story better. The context of a sound may often provide enough clues to interpret the meaning of onomatopoeic words [6]. There are five kinds of onomatopoeia meaning, which are as the typical of objects, forming the name of actions, indicator of the situation, forming of the character's emotions and providing certain effect for a reader [7].

\section{Method}

\subsection{Objectives of the Research Questions}

According to the background, this research will answer the following questions:

- What is the type of French onomatopoeia in webtoon 'Wonderwall' by Sena Loli?

- What is the meaning of French onomatopoeia in webtoon 'Wonderwall' by Sena Loli?

This research is a qualitative study which was aimed at describing the type and meaning of French onomatopoeia in webtoon 'Wonderwall' by SenaLoli.

\subsection{Research Method}

This research is a qualitative study. The subject of this research is webtoon entitled 'Wonderwall' episode 1-10 by Sena Loli, which had been translated to French. The webtoon 
'Wonderwall' was chosen as the subject of the research because it's one of the most read webtoon in LINE webtoon, and sometimes it's on the list of the top five webtoons. Data were collected by using an observation method with uninvolved conservation observation technique and note-taking technique. Then, analysis of data uses an integral method to describe the type and meaning of onomatopoeia simultaneously.

\section{Result and discussion}

The results of the analysis showed that in webtoon 'Wonderwall' by SenaLoli there are 26 data were classified into five types of onomatopoeia that imitate the sound of human (10 data), animal (2 data), nature ( 2 data), object (11 data), and human daily activities ( 1 data). There are five meanings of onomatopoeia that used in the webtoon, which is onomatopoeia as the typical of objects, forming the name of actions, an indicator of the situation, forming of the character's emotions and providing a certain effect for a reader.

\subsection{Onomatopoeia that Imitates the Sound of Human}

Onomatopoeia sound of human is the imitation of sound produced by human verbal and nonverbal.it was found some onomatopoeia of human sounds in this webtoon. Some of data samples are explained below.

\subsubsection{Achoo!}

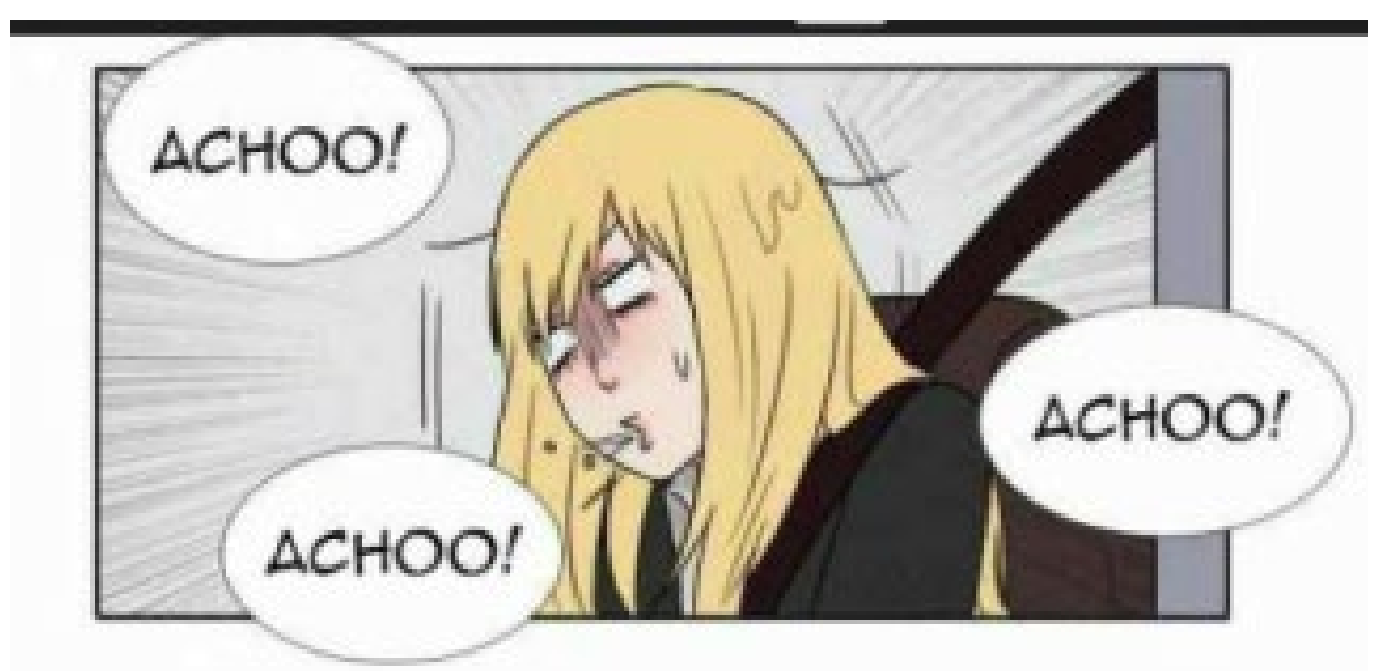

Figure 1. Onomatopoeia 'achoo!'

The word 'achoo!' represent the sound of someone sneezing. The onomatopoeia 'achoo!' then classified into primary onomatopoeia that imitates the sound of a human. Then, the meaning of this onomatopoeia is as an indicator of the situation of the main role. 


\subsubsection{Booooouhhooouhooubouuuhouu}

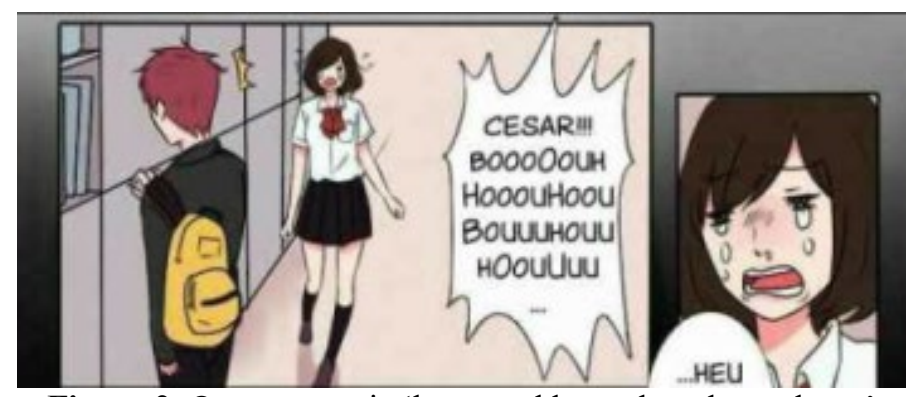

Figure 2. Onomatopoeia 'booooouhhooouhooubouuuhouu'

Onomatope 'booooouhhooouhooubouuhhouu' in figure 2 indicate the expression of crying or sad. The onomatopoeia is classified into primary onomatopoeia which imitates the sound of a human. Then based on the figure, we can conclude that the meaning of onomatopoeia is as a forming of the character's emotions.

\subsubsection{Stap}

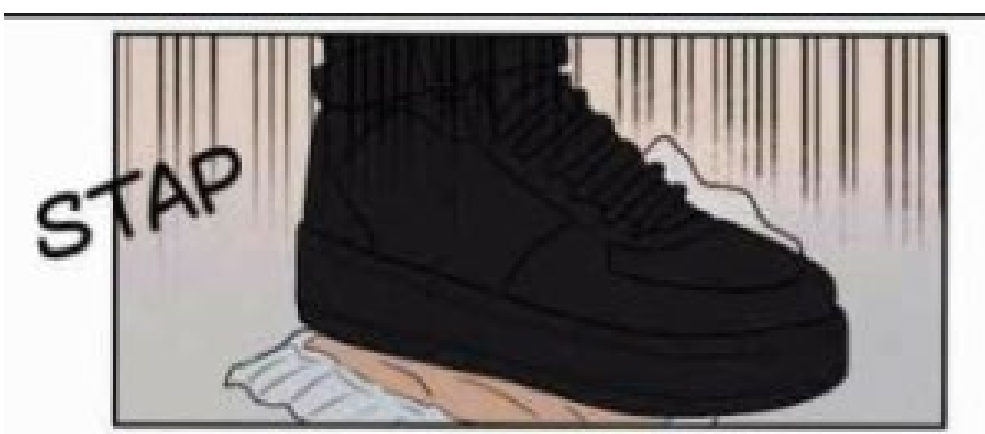

Figure 3. Onomatopoeia 'stap'

The figure shows there is an onomatopoeia 'stap' in webtoon which is classified into secondary onomatopoeia because this onomatopoeia is produced by the integration between the sound of an object and an action. The meaning of onomatopoeia 'stap' is as a forming the name of actions.

\subsection{Onomatopoeia that Imitates the Sound of Animal}

The onomatopoeia of animal is an imitation of the animal sound. There is 2 onomatopoeia of animal in the webtoon 'Wonderwall', such as: 


\subsubsection{Cirpcirp}

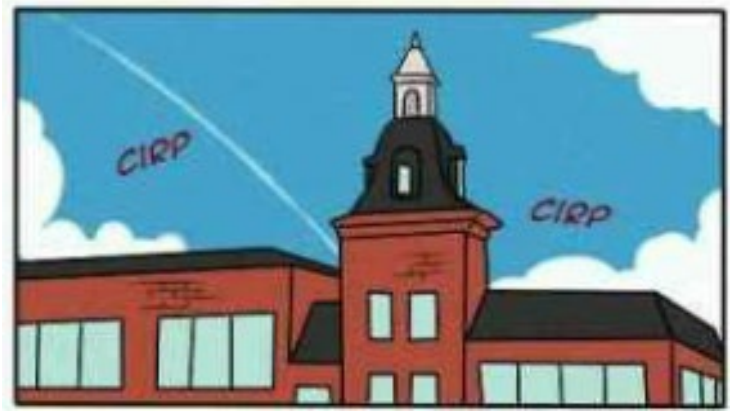

Figure 6. Onomatopoeia 'cirpcirp'

In figure 6 , it can be seen that there are onomatopoeia 'cirpcirp' which indicate the sound of a bird chippering in the schoolyard, in the morning. This onomatopoeia is classified into the primary onomatopoeia which imitates the sound of an animal. Then, the onomatopoeia 'cirpcirp' has a meaning as a type of an object.

\subsection{Onomatopoeia that Imitates the Sound of Nature}

Onomatopoeia the sound of nature is an imitation sound produced by natural objects, such as the sound of the sea water, the sound of the wind. These are the example of onomatopoeia the sound of nature in webtoon 'Wonderwall'.

\subsubsection{Shhhh}

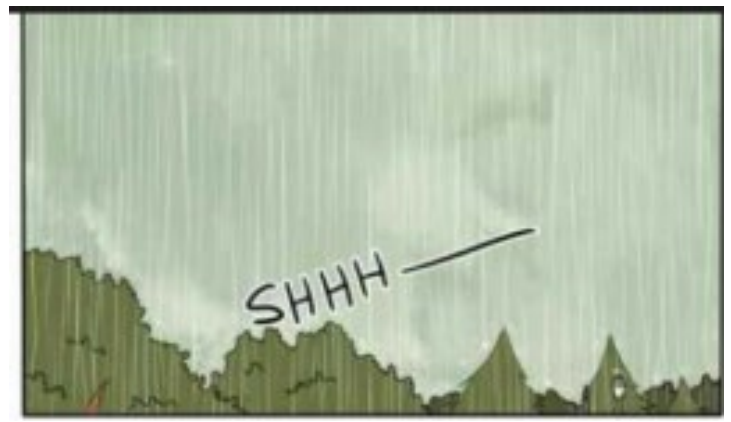

Figure 7. Onomatopoeia 'shh'

Onomatopoeia 'shh' in webtoon wonderwall indicates that the situation is in heavy rain. The onomatopoeia 'shhh' into primary onomatopoeia that imitates the sound of nature, because the sound 'shhh' is produced by the natural object, which is the rain. The meaning of this onomatopoeia is as an indicator of the situation, so the reader can imagine the situation from the story. 


\subsection{Onomatopoeia that Imitates the Sound of Object}

Onomatopoeia of object is an imitation sound produced by an object. There is some onomatopoeia of objects in webtoon 'Wonderwall'. Here is provided some examples.

\subsubsection{Screech}

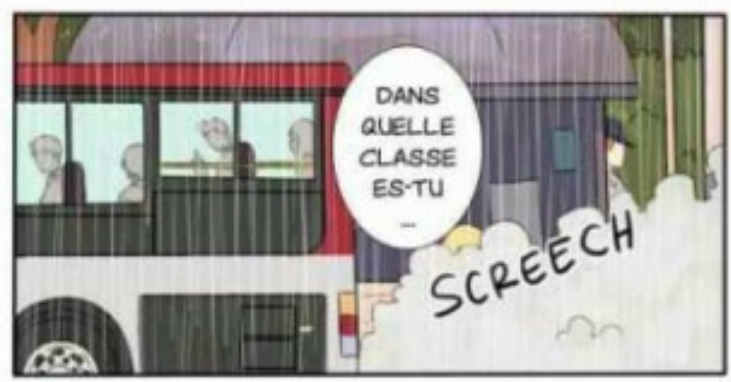

Figure 9. Onomatopoeia 'screech.'

Figure 9 shows there is a bus stop at a bus station. The onomatopoeia 'screech' indicates the sound of bus brakes. This onomatopoeia is classified into primary onomatopoeia that imitates the sound of the object. The meaning of this onomatopoeia is as a forming the name of actions.

\subsubsection{Flop}

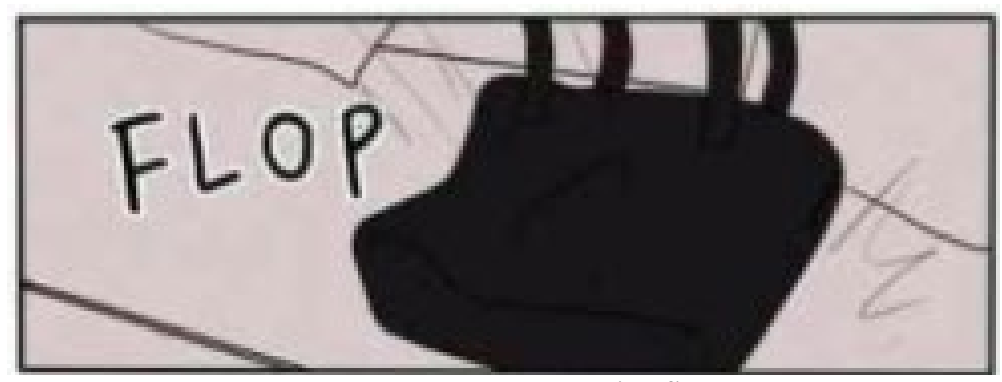

Figure 11. Onomatopoeia 'flop.'

Figure 11 shows a situation when Jessy is coming home and then put her bag on the sofa. There is an onomatopoeia 'flop' in the webtoon that classified into secondary onomatopoeia which imitate the sound of the object. The meaning of onomatopoeia 'flop' is as a type of objects. 


\subsubsection{Thump!}
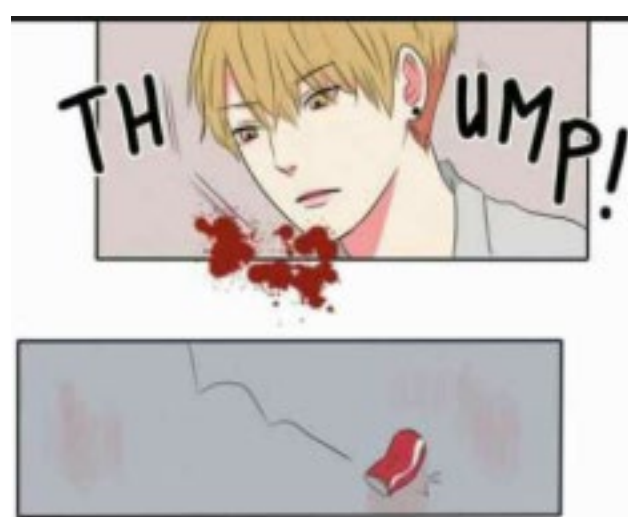

Figure 12. Onomatopoeia 'thump!'

Figure 12 shows the situation when Sean is angry because his head was hit by a coke bottle. There is an onomatopoeia 'thump!' which produced when a coke bottle hit the head. This onomatopoeia is classified into secondary onomatopoeia which imitates the sound of an object to give a certain effect for a reader.

\subsection{Onomatopoeia that Imitates the Sound of Human Daily Activities}

The researcher found 1 data of onomatopoeia that imitate the sound of daily human activities.

\subsubsection{Tip tap}

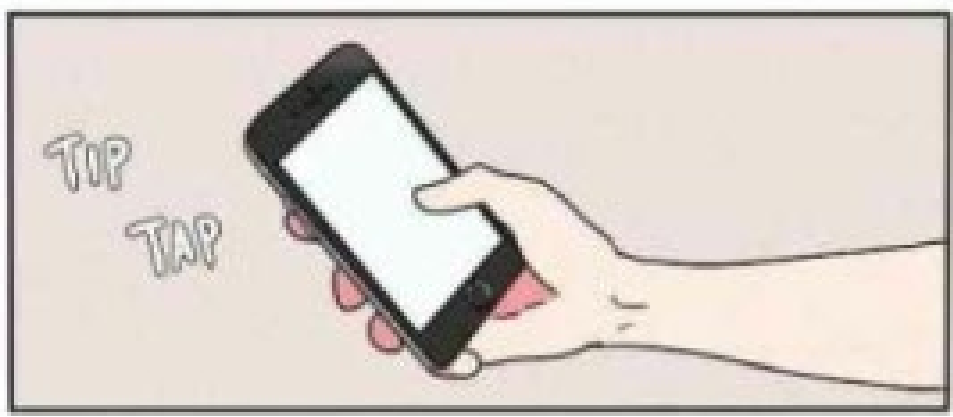

Figure 13. Onomatopoeia 'tip tap.'

Figure 13 shows the situation when Jessy is typing a message on her phone; then the touch produced the sound 'tip tap'. The onomatopoeia 'tip tap' is classified into secondary onomatopoeia which imitates the sound of daily human activity. Using a phone is one of the activities we do every day. 


\section{Conclusion}

There are two types of onomatopoeia found in webtoon 'Wonderwall', the primary and secondary onomatopoeia which imitate the sound of human, the sound of the animal, the sound nature, the sound of the object, and the sound of daily human activities. Furthermore, there are five kinds of onomatopoeia's meaning, such as onomatopoeia as the typical of objects, forming the name of actions, an indicator of the situation, forming of the character's emotions and providing a certain effect for a reader.

Acknowledgments. A great thanks to Mrs. Roswita Lumban Tobing who has given me the opportunity to write and be my collaborator in this research. Also, thanks to all who have helped me writing this article.

\section{References}

[1] D. M. Putri and E. E. Lubis, "Pengaruh Media Sosial LINE Webtoon Terhadap Minat Membaca Komik Pada Mahasiswa Universitas Riau," JOM FISIP, vol. 5, no. 1, pp. $1-$ $15,2018$.

[2] K. Kambara and K. Tsukada, "Onomatopen: painting using onomatopoeia," in International Conference on Entertainment Computing, 2010, no. September, pp. $43-$ 54.

[3] M. F. Assaneo, J. I. Nichols, and M. A. Trevisan, "The Anatomy of Onomatopoeia," PLoS One, vol. 6, no. 12, p. e28317, Dec. 2011.

[4] P. Enckell and P. Rézeau, Dictionnaire des Onomatopées. Paris: Presses Universitaires de France, 2003.

[5] H. Seyyedi and E. Akhlagi, "The Study of Onomatopoeia in the Muslims' Holy Write : Qur'an,” Lang. India, vol. 13, no. May, pp. 16-24, 2013.

[6] S. Ullman, Semantics: An Introduction to The Science of Meaning. Oxford: Basil Blackwell, 1962.

[7] G. A. Putri, "Analisis Bentuk dan Makna Onomatope Bahasa Korea dalam Webtoon ‘DICE’ Stage 33-38 Karya Yun Hyeon Seok,” Universitas Gadjah Mada, 2017. 